\title{
Social conditions and immune response in human immunodeficiency virus-seropositive pregnant women: a cross-sectional study in Brazil
}

\author{
Aletheia Soares Sampaio ${ }^{[1],[2], ~ A n a ~ L u c i a ~ R i b e i r o ~ d e ~ V a s c o n c e l o s ~}{ }^{[1]}$, \\ Clarice Neuenschwander Lins de Morais ${ }^{[3]}$, George Tadeu Nunes Diniz ${ }^{[1]}$, \\ Anna Lígia de Castro Figueiredo ${ }^{[2]}$ and Sílvia Maria Lucena Montenegro ${ }^{[4]}$
}

[1]. Departamento de Saúde Coletiva, Centro de Pesquisas Aggeu Magalhães, Fundação Oswaldo Cruz, Recife, PE, Brasil. [2]. Serviço de Atendimento Especializado em HIV/AIDS, Centro Integrado de Saúde Amaury de Medeiros, Universidade de Pernambuco, Recife, PE, Brasil. [3]. Laboratório de Virologia e Terapia Experimental, Centro de Pesquisas Aggeu Magalhães, Fundação Oswaldo Cruz, Recife, PE, Brasil. [4]. Departamento de Imunologia e Imunopatologia Celular, Centro de Pesquisas Aggeu Magalhães, Fundação Oswaldo Cruz, Recife, PE, Brasil.

\begin{abstract}
Introduction: The functioning of the immune system during pregnancy is altered in both human immunodeficiency virus (HIV)infected and uninfected women. Unfavorable socioeconomic conditions have been indicative of higher morbidity and mortality and worsening of the immune system. The aim of this study was to correlate social status with levels of interleukin (IL)-10 (noninflammatory) and interferon-gamma (IFN- $\gamma$; inflammatory) cytokines. Methods: A cross-sectional study was conducted with three groups of women: 33 pregnant HIV-infected (G1); 40 non-pregnant, HIV-infected (G2); and 35 pregnant, HIV-uninfected. To measure the social status, a compound indicator called the social status index (SSI), was established using sociodemographic variables (i.e., education level, housing conditions, per capita income, and habitation and sanitary conditions). Results: The HIV-infected women had a higher proportion of unfavorable SSI ( $73 \%$ and $75 \%$ of G1 and G2, respectively). There were significantly lower IL-10 levels in the G1 group with both unfavorable and favorable SSI than in the other groups. No significant difference in IFN- $\gamma$ levels was observed among groups. However, the G1 group had higher IFN- $\gamma$ values among both favorable and unfavorable SSI groups. Conclusions: Higher rates of unfavorable conditions, including lower education levels, IL-10 levels, and a trend for higher IFN- $\gamma$ levels, were identified among HIV-infected women, pregnant and non-pregnant. These factors may interfere in health care and lead to poor outcomes during pregnancy. Therefore, we suggest that health policies could be created to specifically address these factors in this population.
\end{abstract}

Keywords: Acquired immunodeficiency syndrome. Pregnancy. Poverty. Interleukin-10.

\section{INTRODUCTION}

In Brazil, the feminization of the acquired immune deficiency syndrome (AIDS) epidemic among heterosexuals infected with the human immunodeficiency virus (HIV) has led to increased cases among pregnant women, introducing mother-to-child transmission (MTCT) as a public health problem. From January 1980 to June 2016, 16,612 AIDS cases among children aged $<5$ years were reported to the Brazilian Ministry of Health (MS); $93 \%$ of these cases were related to MTCT. From January 2000 to June 2015, 99,804 cases of HIV infection in pregnant women were reported in the Notifiable Diseases Information System, $16.2 \%$ of whom from the Brazilian Northeast ${ }^{1}$. The

Corresponding author: Dra. Aletheia Soares Sampaio.

e-mail: aletheia@cpqam.fiocruz.br

Received 4 July 2017

Accepted 30 November 2017
AIDS epidemic in Brazil has also affected disadvantaged social classes, highlighting the susceptibility of individuals with lower education levels ${ }^{2,3}$.

Unfavorable socioeconomic conditions and low education levels have been identified as indicators of poor adherence to therapy and lack of safe sex practices. Essentially, poverty corresponds to non-satisfaction with basic human needs, such as food, shelter, clothing, and health care ${ }^{4}$. Precarious social conditions can negatively affect immune system function ${ }^{5,6}$. Many factors lead to immune system alterations in people with HIV, including the infection process itself and unfavorable living conditions. These alterations may lead to a diminished functioning of $\mathrm{T}$ cells, including cluster of differentiation $4^{+}$ $\left(\mathrm{CD} 4^{+}\right)$and cluster of differentiation $8^{+}\left(\mathrm{CD}^{+}\right)$lymphocytes, reduction in the complementary system components, compromised phagocytosis and cytokine response [interleukin (IL)-10 and interferon-gamma (IFN- $\gamma$ )], and changes in the production of different antibody types ${ }^{7-9}$. Other physical, psychological, and physiological stress factors may also interfere with the immune response ${ }^{10}$. 
In pregnancy, the immune system function is altered in both HIV-infected and uninfected women ${ }^{11-13}$, which is mediated by factors produced by the fetus and hormonal changes that act as modulators of cytokine production ${ }^{14}$. The impact of HIV infection on the network of cytokines and maintenance of pregnancy has not been well investigated ${ }^{15-17}$, but the proinflammatory effects of maternal HIV in MTCT have been studied. One explanation for transplacental HIV transmission is that viral proteins may have a direct pro-inflammatory effect on placental cells and the development of the infant' immune system, which may increase the risk of an HIV infection ${ }^{18-20}$. IL10 has a predominantly anti-inflammatory role and is essential for maintaining the different stages of pregnancy ${ }^{21-23}$. Moreover, IFN- $\gamma$ has a predominantly inflammatory effect and plays an important role during the acute phase of HIV infection ${ }^{24}$.

Differences in the survival rates of HIV patients have been observed in various sociodemographic contexts, and it is unclear whether this is due to biological differences or access to care. Patroclo and Medronho, in 2007, showed that people living in slums were 3.7 times more likely to not have an immune response after antiretroviral therapy (ART) than those not living in slums ${ }^{25}$. Based on these facts, the aim of study was to describe the sociodemographic profile of pregnant women with HIV infection and examine the correlation between their social status and levels of non-inflammatory and inflammatory cytokines.

\section{METHODS}

A cross-sectional exploratory study was conducted in three groups of women: 33 HIV-infected pregnant (G1), 40 HIV-infected non-pregnant (G2), and 35 HIV uninfected pregnant (G3). Participants were recruited from the HIV/ AIDS specialized care service located at the Centro Integrado de Saúde Amaury de Medeiros (CISAM) in Recife, the capital City of Pernambuco State, in northeast Brazil. Convenience sampling was conducted between August 2010 and July 2011. All participants had to be at least 18 years of age. In the HIVinfected groups, the diagnosis was confirmed by serology, as recommended by MS (Ordinance No 59/GM/MS, January $28^{\text {th }}$, 2003) or by rapid HIV tests, according to Decree No 34/SVS/ MS, July $28^{\text {th }}, 2005$. Participants also had to provide a signed free informed consent document. All data were collected by a trained investigator.

\section{Ethical considerations}

The study was conducted after ethical clearance from the Research Ethics Committee of the Aggeu Magalhães Research Center/Oswaldo Cruz Foundation (FIOCRUZ), CAAE 0007.0.095.000-10. The procedures of this study were conducted in accordance with the ethical standards of this committee and the 1964 Declaration of Helsinki and its subsequent amendments.

The inclusion criteria were as follows: G1 group, HIV asymptomatic women without AIDS-opportunistic infections with confirmed diagnosis during or before the current pregnancy; G2 group, without pregnancy or abortion in the 18 months preceding the study; and G3 group, undergoing lowrisk prenatal care at the CISAM clinic. The exclusion criteria were: using ART; having hepatitis B or C, or syphilis; having an autoimmune disease, diabetes, hypertension, arthritis, or cancer; or taking immunosuppressants drugs.

Measurement of the HIV viral load and the T-CD4 ${ }^{+}$ lymphocytes count was conducted by the Central Public Health Laboratory of Pernambuco using the HIV-1 RNA 3.0 Assay (b-DNA) kits manufactured by Siemens Healthcare Diagnostics ${ }^{\circledR}$, Berkeley, United States of America (USA), following the standards of the manufacturer and the flow cytometry technique. The IL-10 and IFN- $\gamma$ cytokines were measured in plasma by enzyme-linked immunosorbent assay using the R \& D Quantikine kits System ${ }^{\circledR}$, Bio-Techne Corporation Brands, Minneapolis, USA, specific for each cytokine according to the manufacturer's instructions. The lower limits for detection for IL-10 and IFN- $\gamma$ were $3.9 \mathrm{pg} / \mathrm{mL}$ and $8 \mathrm{pg} / \mathrm{mL}$, respectively. In pregnant women (G1 and G3 groups), the IL-10 and IFN- $\gamma$ levels were measured during the second trimester of pregnancy (from 12 to 24 weeks).

To measure the social status of women, a compound indicator, called the social status index (SSI), was constructed using four sociodemographic variables (i.e., education level, housing conditions, per capita income, and household sanitary conditions) based on previous studies ${ }^{26,27}$. The four sociodemographic variables were scored as zero (unsatisfactory) or one (satisfactory) based on the following conditions. Education levels were scored as zero or one for women with $\leq 8$ or $>8$ years of study, respectively, assuming that women with higher levels of education have a better understanding of their health status and self-care. For housing conditions, a score of one or zero was assigned to women who were living in their own home or had other housing conditions (i.e., rented accommodation, living with relatives, or others), respectively. The monthly per capita income was measured by dividing total household income by the number of people living in the home. Women were scored as zero if they had a monthly per capita income less than or equal to half the minimum wage of $\mathrm{R} \$ 272.50$ (Brazilian real) or one if their monthly per capita income was $>\mathrm{R} \$ 272.50$. The minimum wage at the time of data collection (R $\$ 545)$ was equivalent to US\$300 per month. The cutoff points for establishing the scores were based on the level of monthly per capita income used by the Brazilian Government for inclusion of families in its social programs. Lastly, for household sanitary conditions, women were scored as one if they lived in household with proper sanitation, including the presence of a closed sanitary pit, piped water, and regular garbage collection, or zero if these sanitary services were absent. A composite score was calculated after each component was scored; composite scores of $\geq 3$ and $<3$ were considered as favorable and unfavorable SSI, respectively.

For habits, consumption of alcohol or cigarettes, at the moment of the study or in the last 30 days was considered without detail the amount of cigarettes or alcohol consumed, because it wasn't the main objective of the study.

Data were analyzed using R software package, version 3.1.2, 2014, from R Foundation for Statistical Computing, Vienna, Austria. The Bartlett test was used to verify the assumption of 
homogeneity for the quantitative variables analysis. Medians were compared using the Kruskal-Wallis non-parametric test for multiple comparisons. This approach uses the Mann-Whitney test as a post hoc analysis to confirm the difference among groups and has been also used for correcting multiple testing by Bonferroni adjustment. The analysis of variance test was used to compare mean ages among groups, and post hoc analysis was performed by Tukey test. The Pearson's chi-square test for count data was performed when possible; otherwise, Fisher's exact test was used. The significance level was set at $5 \%$. Spearman's correlation test was used to quantify the correlation between the social status of women (favorable or unfavorable SSI) and cytokine profile (IL-10 and INF- $\gamma$ ).

\section{RESULTS}

The age rages of women in the study groups were as follows: G1 group, 18-40 years [mean, 26 years; standard deviation (SD), 7 years]; G2 group, $20-47$ years (mean, 30 years; SD, 6 years); and G3 group, 19-36 years (mean, 25 years; SD, 5 years). There were differences in the mean age between the G1 and G2 groups $(p=0.01)$, but not between the G1 and G3 groups $(p=0.64)$.

The sociodemographic profile of women is shown in Table 1. There were significant differences in the place of residence among groups $(p=0.04)$, with a greater proportion of women (about $60 \%$ in the G1 and G3 groups) living in Recife. Most women in the G2 $(65 \%)$ were from another town in Pernambuco. The education level of pregnant women without HIV (G3) was significantly higher than that in the other groups ( $p<0.01$ ). Approximately $82.9 \%$ of the G3 group had more than eight years of education compared to that of the G1 (63.6\%) and G2 (42.5\%) groups. Women in the G3 had significantly better incomes $(p=0.03)$ than those of the other groups. Approximately $48.6 \%$ of women in the G3 group earned more than twice the minimum wage per month compared to that earned by women in the G2 (25\%) and G1 (18.2\%). A significantly higher proportion of pregnant women $(72.7 \%$ and $68.6 \%$ in the G1 and G3, respectively) were unemployed. The percentage of unemployed women in the G2 was $45 \%$. There were no significant differences in the living conditions among groups; however, the majority of women from all groups shared their home with three or more people $(78.8 \%$ in G1, $85 \%$ in G2, and $77.2 \%$ in G3) and lived in a house with two or three rooms (87.9\% in G1, 95\% in G2 and $97.1 \%$ in G3). However, only $45.6 \%, 45 \%$, and $51.4 \%$ of women from the G1, G2, and G3 groups, respectively, lived in their own home. Furthermore, no significant differences in home sanitary conditions were found among groups, and most women reported to have good sanitation at home $(72.7 \%, 85 \%$, and $88.6 \%$ in the G1, G2, and $\mathrm{G} 3$ groups, respectively). Women in the G1 and G2 groups had the worst rating for the SSI; approximately $72.7 \%$ and $75 \%$ of women in the G1 and G2, respectively, had unfavorable social conditions compared to those of women in the G3 $(42.9 \%$; $p<$ 0.01 ). Furthermore, there were $29.8 \%$ more pregnant women in the G1 group with unfavorable social conditions than that in the G3 group. Among the HIV-infected groups (G1 and G2), there were $2.3 \%$ more women with unfavorable social conditions in the $\mathrm{G} 2$ group than that in the G1.
Information regarding the gestational age, immunological and virological status, habits, and partners of women in each group are summarized in Table 2. More than $70 \%$ of pregnant women $(75.8 \%$ and $74.3 \%$ in groups $\mathrm{G} 1$ and $\mathrm{G} 3$, respectively; $\mathrm{p}=1.00$ ) initiated prenatal care during the first trimester of pregnancy with no difference between them. HIV-infected women in the G1 and $\mathrm{G} 2$ groups ( $60.7 \%$ and $95 \%$, respectively) had a significantly higher number of living children than those in the G3 group $(42.9 \% ; \mathrm{p}<0.01)$. Among the HIV-infected women, approximately $63.6 \%$ and $52.5 \%$ of women from the G1 and G2 groups, respectively, had knowledge regarding their HIV diagnosis during the last three years before the study ( $p<0.01$ ), and $51.5 \%$ of women in the G1 group had been diagnosed less than one year before the study. There was no significant difference in moment of diagnosis among groups $(p=0.29)$. In the G1, 84.8\% of women were diagnosed during the current or previous pregnancy or delivery, and $51.5 \%$ were diagnosed during the current pregnancy (i.e., less than one year ago). A large proportion in the $\mathrm{G} 2$ group were also diagnosed during a previous pregnancy (82.5\%). There were no differences in the immune status for HIV infection among groups $(p=0.72)$. Approximately $63.6 \%$ and $77.5 \%$ of women in the G1 and G2 groups, respectively, had T-CD4 lymphocyte levels $>350$ cells $/ \mathrm{mm}^{3}$. Similarly, no differences in the HIV viral load levels were found among groups $(p=0.55)$. The percentage of women who had a viral load of $>1,000$ copies $/ \mathrm{mL}$ in the G1 and G2 groups was $63.6 \%$ and $77.5 \%$, respectively. A higher percentage of pregnant women (12.2\%) had an unknown viral load than that in women from the G2 group (5\%). Regarding lifestyle habits, a higher percentage of HIV-infected women (G1 and G2) had smoked and consumed alcohol. Approximately, $18.2 \%$ and $17.5 \%$ of women with HIV in the G1 and G2 groups, respectively, had used illicit drugs. A significantly high number of pregnant women had reported having only one steady sexual partner ( $96.9 \%$ and $97.1 \%$ in groups G1 and G3, respectively). In the $\mathrm{G} 2$ group, $30 \%$ of women reported having more than one sexual partner. When asked about the partner's serological HIV status, $46.9 \%$ and $21.4 \%$ of HIV-infected women in the G1 and G2 group, respectively, said they did not know their partner's HIV status $(p<0.01)$. However, $67.6 \%$ of women in the G3 group had no knowledge regarding their partner's serological status. Among the women who had knowledge regarding their partner's HIV status, there were $31.3 \%$ and $35.7 \%$ serum discordant couples in the G1 and G2 groups, respectively.

Among the three study groups, the IL-10 levels were highest in the G2 group and lowest in the G1 group (Figure 1A; $\mathrm{p}<0.01$ ). Although the median IFN- $\gamma$ levels in all groups were below the detection limit, there were significant differences $(p<0.01)$ when the G1 group was compared with G2 and G3. The G1 group had higher IFN- $\gamma$ levels than those in the G2 and G3 groups (Figure 1B).

The IL-10 levels in women with a favorable SSI were significantly lower in the G1 group than those in the G2 $(p<0.01)$ and $\mathrm{G} 3(\mathrm{p}=0.01)$ groups $($ Figure $2 \mathrm{~A})$. Among women with an unfavorable SSI, the IL-10 levels were significantly lower in the G1 than those in the G2 and G3 ( $p<0.01$ for both; Figure 2B). 
TABLE 1: Sociodemographic profile of women, Recife, 2011.

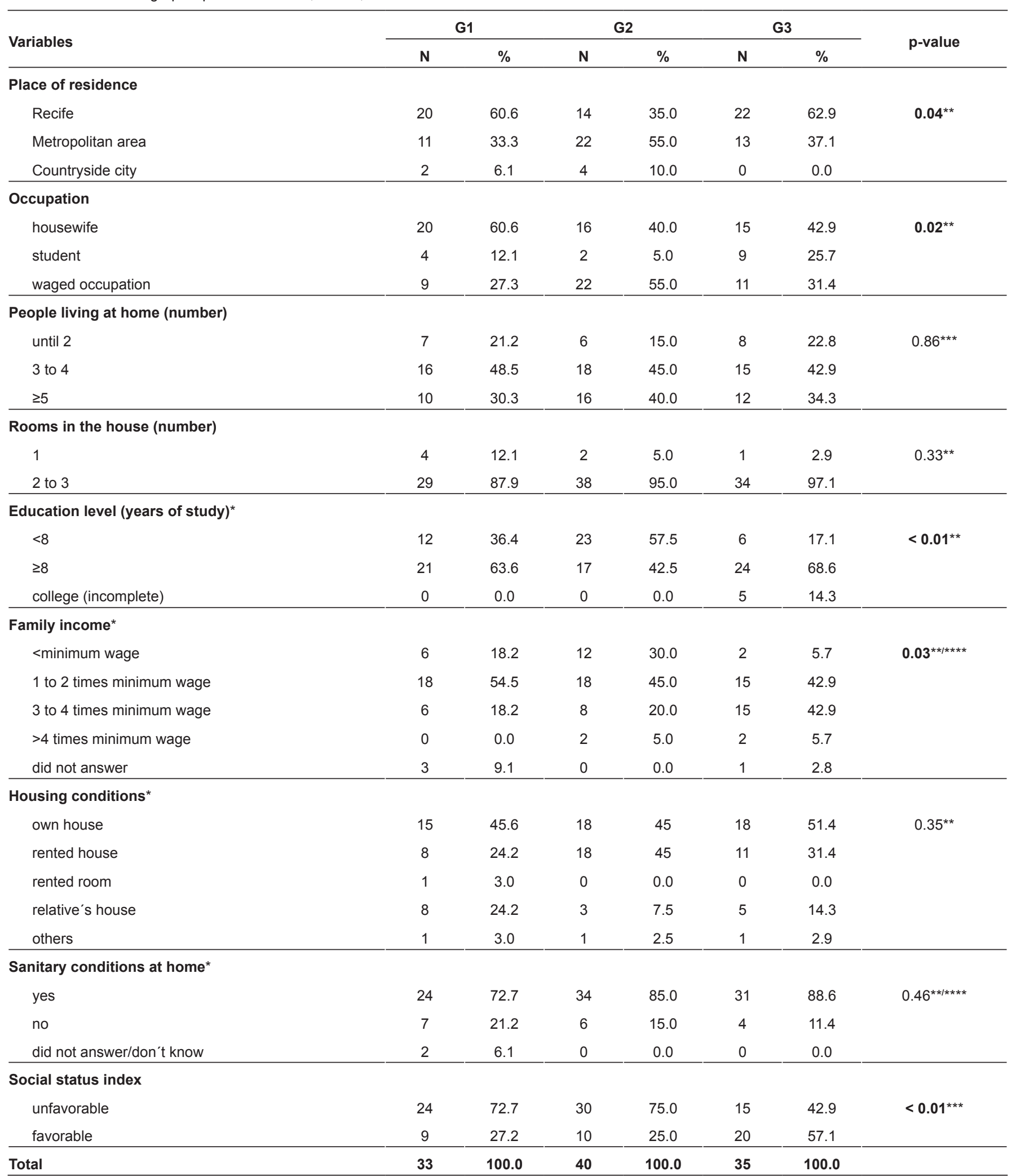

G1: pregnant and HIV-infected; G2: non-pregnant and HIV-infected; G3: pregnant and HIV-uninfected; HIV: human immunodeficiency virus; SSI: social status index. "Variables used to determine the SSI. The monthly per capita income used in the SSI was established by dividing the total household income by the number of people living in the house. P-values were calculated using **Fisher's exact test and ${ }^{* * *}$ Pearson's chi-square test. ${ }^{* * *}$ Participants who did not answer or did not know the answer were not included in the hypothesis test. 
TABLE 2: Gestational age, immunological and virological status, habits, and partner details of the study groups, Recife 2011.

\begin{tabular}{|c|c|c|c|c|c|c|c|}
\hline \multirow[b]{2}{*}{ Variables } & \multicolumn{2}{|c|}{ G1 } & \multicolumn{2}{|c|}{ G2 } & \multicolumn{2}{|c|}{ G3 } & \multirow[t]{2}{*}{ p-value } \\
\hline & $\mathbf{N}$ & $\%$ & $\mathbf{N}$ & $\%$ & $\mathbf{N}$ & $\%$ & \\
\hline \multicolumn{8}{|c|}{ Beginning of prenatal care (trimester) } \\
\hline $1^{\text {st }}$ & 25 & 75.8 & - & - & 26 & 74.3 & $1.00^{*}$ \\
\hline $2^{\text {nd }}$ & 8 & 24.2 & - & - & 9 & 25.7 & \\
\hline $3^{\text {rd }}$ & 0 & 0.0 & - & - & - & - & \\
\hline \multicolumn{8}{|c|}{ Living children (number) } \\
\hline 0 & 13 & 39.3 & 2 & 5 & 20 & 57.1 & $<0.01^{*}$ \\
\hline 1 & 10 & 30.3 & 9 & 22.5 & 11 & 31.4 & \\
\hline 2 & 5 & 15.2 & 17 & 42.5 & 3 & 8.6 & \\
\hline$\geq 3$ & 5 & 15.2 & 12 & 30.0 & 1 & 2.9 & \\
\hline
\end{tabular}

\begin{tabular}{|c|c|c|c|c|c|c|c|}
\hline$<1$ & 17 & 51.5 & 2 & 5.0 & - & - & $<0.01^{* * / * * *}$ \\
\hline 1 to 3 & 4 & 12.1 & 19 & 47.5 & - & - & \\
\hline$>3$ and $<5$ & 6 & 18.2 & 10 & 25.0 & - & - & \\
\hline$\geq 5$ & 4 & 12.1 & 8 & 20.0 & - & - & \\
\hline unknown & 2 & 6.1 & 1 & 2.5 & - & - & \\
\hline
\end{tabular}

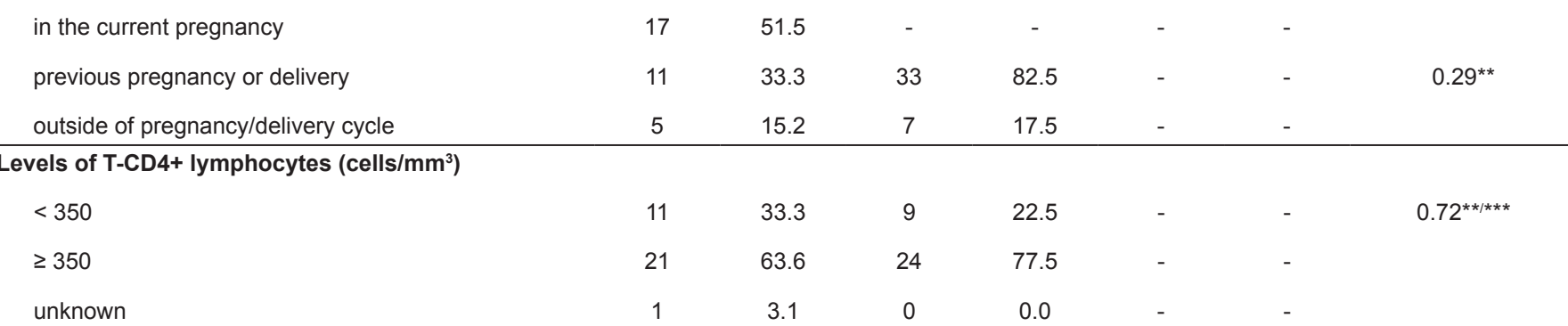

\section{Viral load (copies/ml)}

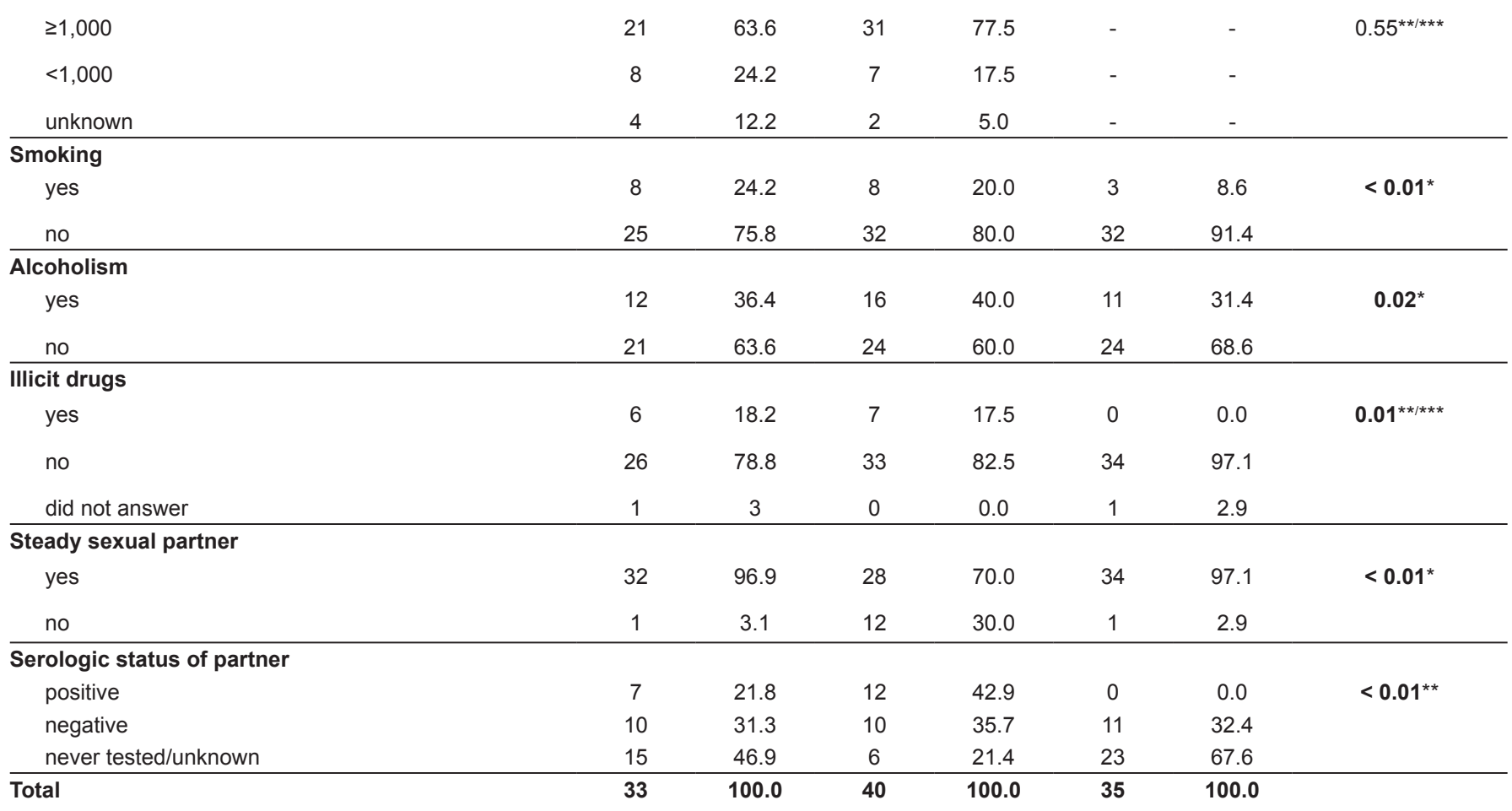

G1: pregnant and HIV-infected; G2: non-pregnant and HIV-infected; G3: pregnant and HIV-uninfected; HIV: human immunodeficiency virus; T-CD4+ lymphocytes: cluster of differentiation $4^{+} \mathrm{T}$ lymphocytes. P-values were calculated using. *Pearson's chi-square test. **Fisher's exact test.

${ }^{* * *}$ Participants who did not answer or did not know the answer were not included in the hypothesis test. 


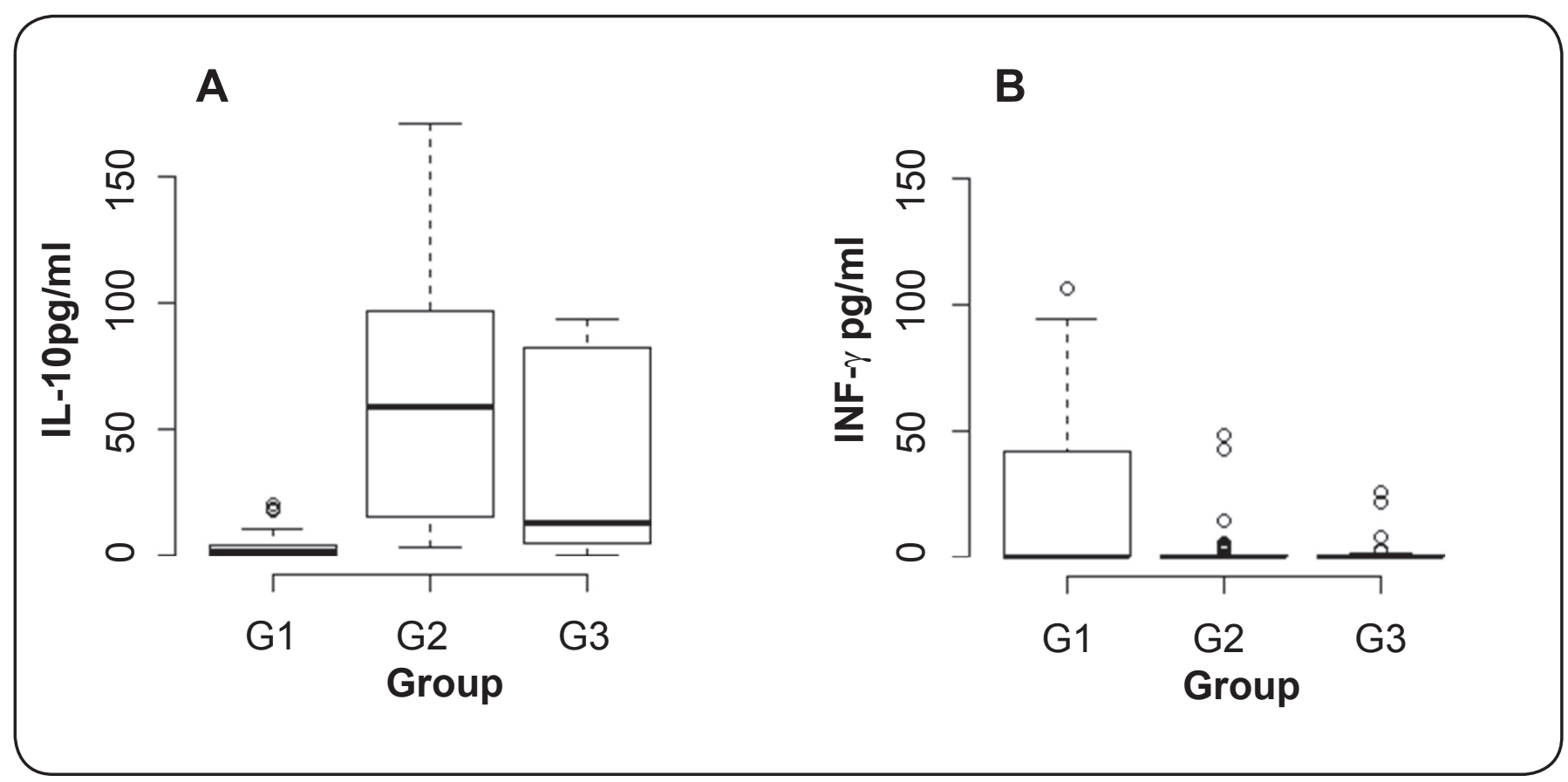

FIGURE 1: Distribution of data related to interleukin-10 and interferon gamma for study groups. IL-10: interleukin-10; G1: pregnant and HIV-infected; G2: non-pregnant and HIV-infected; G3: pregnant and HIV-uninfected; IFN-y: interferon gamma; HIV: human immunodeficiency virus. The following p-values were obtained using the Kruskal-Wallis test and post hoc Mann-Whitney test: A) $p<0.01$ (G1 and G2) and $p<0.01$ (G1 and G3); and B).p<0.01 (G1 and G2) and $p<0.01$ (G1 and G3).

A

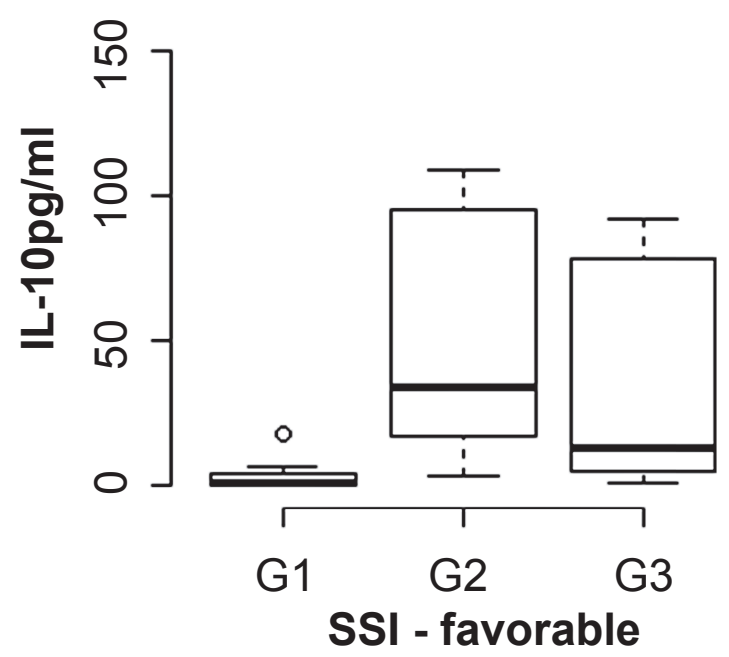

B

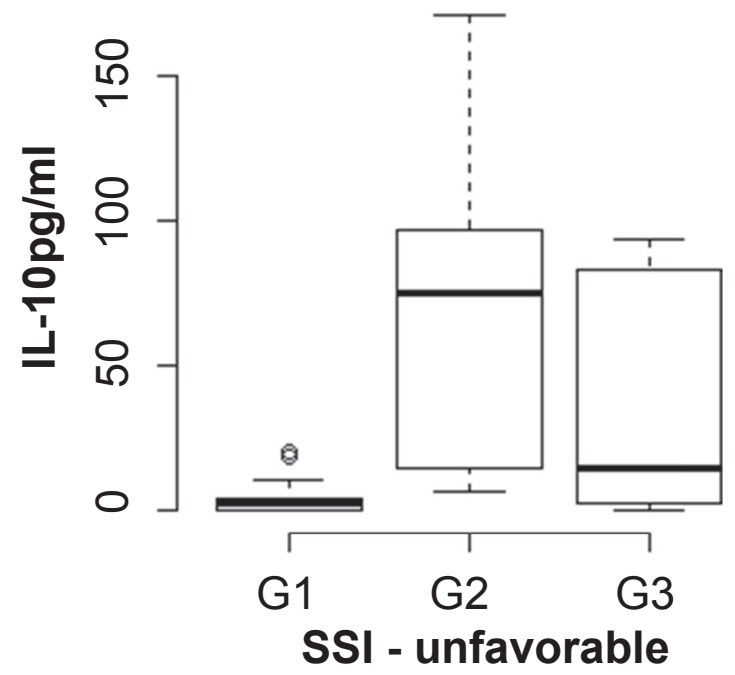

FIGURE 2: Distribution of data related to interleukin-10 for the study groups stratified by socioeconomic status. IL-10: interleukin-10; G1: pregnant and HIV-infected; G2: non-pregnant and HIV-infected; G3: pregnant and HIV-uninfected; IFN-y: interferon gamma; SSI: social status index; HIV: human immunodeficiency virus. The following $p$-values were obtained using the Kruskal-Wallis test and post hoc Mann-Whitney test: A) $p<0.01$ (G1 and G2) and $\mathrm{p}=0.01$ ( $\mathrm{G} 1$ and $\mathrm{G} 3)$; and $\mathrm{B}) \mathrm{p}<0.01(\mathrm{G} 1$ and $\mathrm{G} 2)$ and $\mathrm{p}<0.01$ ( $\mathrm{G} 1$ and $\mathrm{G} 3$ ). 


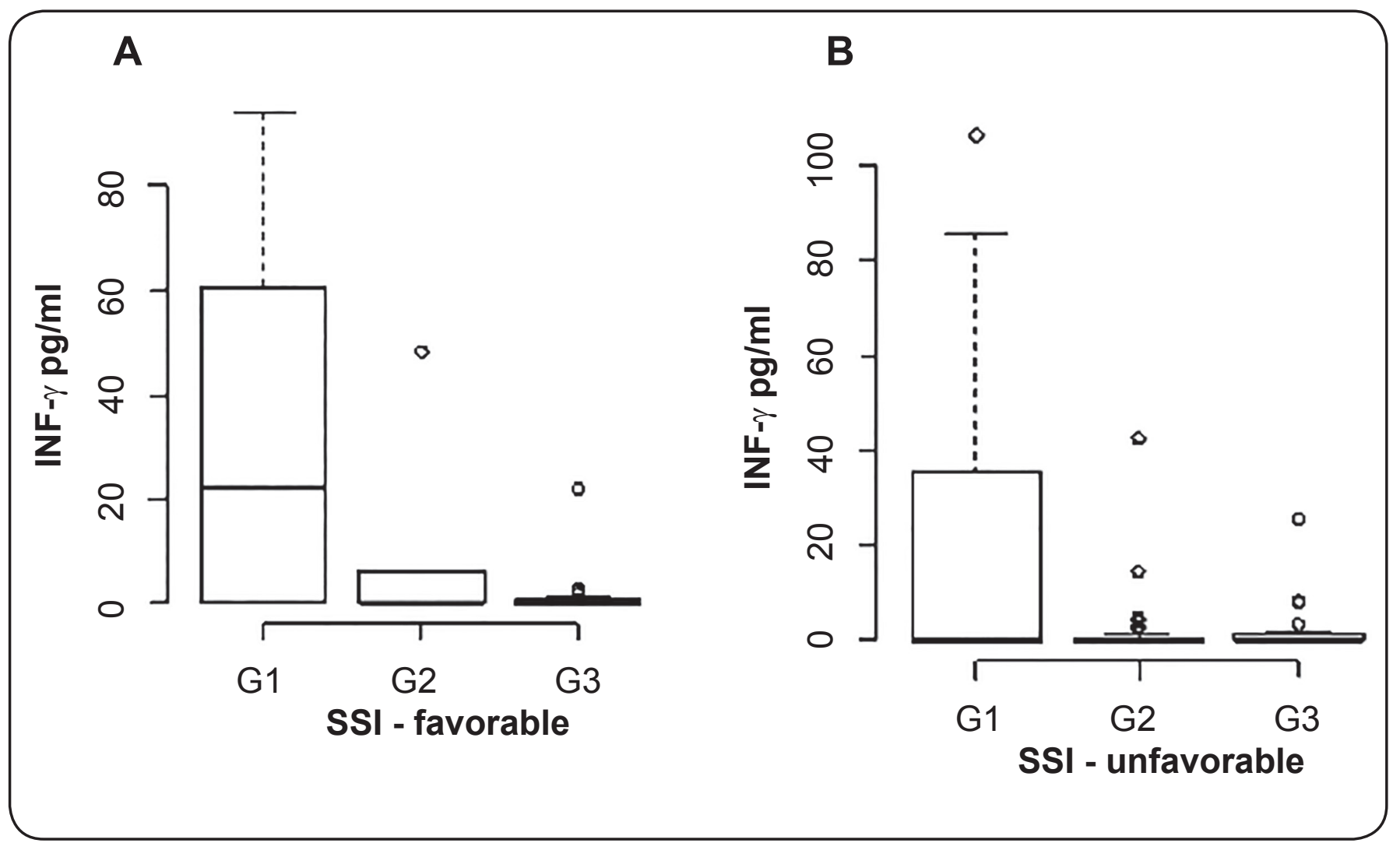

FIGURE 3: Distribution of data related to interferon gamma for the study groups stratified by socioeconomic status. IL-10: interleukin-10; G1: pregnant and HIV-infected; G2: non-pregnant and HIV-infected; G3: pregnant and HIV-uninfected; IFN-y: interferon gamma; SSI: social status index; HIV: human immunodeficiency virus. The following $p$-values were obtained using the Kruskal-Wallis test: $A) p=0.41(G 1$ and $G 2)$ and $p=0.06$ (G1 and G3); and $B$ ) $p=0.24(\mathrm{G} 1$ and $\mathrm{G} 2)$ and $p=0.58(\mathrm{G} 1$ and $\mathrm{G} 3)$.

Among women with a favorable SSI, there was a trend towards higher IFN- $\gamma$ levels in the G1 group, but this relationship was not significantly different among groups (Figure 3A). Although the median IFN- $\gamma$ levels in women with an unfavorable SSI were all below the detection limit, there were no significant differences among groups (Figure 3B). However, the G1 group again showed a trend towards higher IFN- $\gamma$ levels.

\section{DISCUSSION}

In this study, we found that HIV-positive pregnant and nonpregnant women from Northeast of Brazil had significantly lower education, income employment, and social status and higher number of children than those of women without HIV infection. These findings of impoverishment of the AIDS epidemic has been previously reported in others studies in Brazil $^{28-31}$. In a study of HIV-infected women by Friedman et al., in 2011, an inverse correlation was observed between education level and pregnancy, and the risk of pregnancy was $75 \%$ higher among women with up to three years of education than that in women with nine years or more of education ${ }^{29}$. Similar to the low income employment found in our study, it was previously found that there was a lower participation of women with HIV in the labor market than that of men, and that women without any regular income had the highest AIDS incidence and annual growth $\operatorname{rates}^{30}$. The MS (2013) and other researchers ${ }^{2,29,31-34}$ have documented a significant growth in HIV infection among socioeconomically underprivileged women, which is also indicative of the so-called impoverishment and feminization of the AIDS epidemic.

One of the challenges found in socially disadvantaged populations is the difficulty of access to health services. This problem is reflected in the present study by the delay in beginning prenatal care in about $24 \%$ and $26 \%$ of pregnant women in the G1 and G3 groups, respectively, with no significant differences between these groups. Despite this, most women lived in the state's metropolitan area (Recife) with only a small percentage of the HIV-infected groups residing in rural areas.

To characterize the social status as a determinant of health, Fonseca et al. recognized educational level as one of the best indicators of social conditions because it is easily measurable and directly related to income and housing conditions. However, these authors suggested that the various socioeconomic indicators should be examined simultaneously rather than independently ${ }^{35}$. It should be emphasized that smoking and drinking alcohol were more frequent among the HIV-infected (G1 and G2) groups and the use of illicit drugs was present exclusively in those groups. These findings suggest that the higher proportion of HIV-infected women with unfavorable 
SSI may be due to cultural differences that modify behavior in socially underprivileged classes. Nationwide socioeconomic differences in smoking over time are poorly understood ${ }^{36}$. It is worth noting that exposure to illicit drugs during pregnancy may increase MTCT of HIV through a variety of mechanisms, including damage to the placenta, induction of preterm birth, and increased maternal plasma viral load ${ }^{37}$.

The lower levels of IL-10 in the pregnant HIV-infected women (G1) were significantly different from those of the other two groups (G1 and G2). This finding indicates a greater disadvantage in the HIV-infected women because the immunomodulatory role of IL-10, which contributes to a healthy pregnancy, is compromised in these women ${ }^{38}$. These findings were partially similar to the study by Hygino et al. who observed higher levels of IL-10 among HIV-uninfected than in HIV-infected pregnant women $(\mathrm{p}<0.01)$. However, the IL-10 levels were lower in HIV-infected than in HIV-uninfected non-pregnant women ${ }^{39}$.

In contrast, we observed a trend towards higher IFN- $\gamma$ levels in the G1 group compared to that in the other groups. The presence of a pro-inflammatory environment in pregnant women with HIV-infection has been implicated as providing the underlying conditions for negative outcomes and the MTCT of $\mathrm{HIV}^{18}$. Some authors have reported that a pro-inflammatory environment can trigger uterine contractions, and consequently fetal loss or prematurity ${ }^{40}$.

Among women with a favorable SSI, IL-10 levels in the pregnant HIV-infected group (G1) were significant lower than those in the G2 and G3 groups. Similarly, among women with an unfavorable SSI, the IL-10 levels were significantly lower in the G1 group than those in the G2 and G3 groups. These findings suggest that pregnancy and HIV infection mutually contribute to the decrease in IL-10 levels. Based on the findings by Bento et al. ${ }^{41}$ who demonstrated the role of IL-10 in the control of viral replication in pregnant women with HIV, it can be mentioned that pregnant women with HIV, regardless of their SSI, showed a lower protective effect for IL-10. This suggests that pregnant women with HIV have poor immune conditions and therefore, be more vulnerable to maternal morbidity, mortality, and the MTCT of HIV. Although there were no significant differences in the IFN- $\gamma$ levels among groups when stratified by social conditions, there was a trend towards a higher inflammatory response in the G1 group (both favorable and unfavorable SSI groups). The inability to detect a significant relationship was probably related to the small sample size of our study. In people with HIV, regardless of their T-CD4 ${ }^{+}$lymphocyte count, high levels of inflammatory markers have been correlated with an increased progression to AIDS and death ${ }^{42,43}$. Inflammatory cytokines can support HIV replication in trophoblasts, potentially impacting placental inflammation and increasing the risk of MTCT of HIV ${ }^{44}$.

limitation of this study is that convenience sampling was only applied to asymptomatic women. Therefore, it was not possible to standardize the gestational age, $\mathrm{T}-\mathrm{CD} 4^{+}$lymphocyte levels, and HIV viral load levels. Furthermore, the sample size was small. A more detailed analysis with a larger sample size, categorized by levels of lymphocytes, is being conducted in another study by our research group. Despite these limitations, we determined that personal and collective disadvantages invariably increase when pregnant women with HIV infections experience poor social conditions (i.e., low education levels, low household income, adverse living standards, and poor sanitation). Furthermore, malnutrition in people with HIV is multifactorial and maybe caused by either a decreased calorie intake or the infectious process during unfavorable living conditions, which may arise as a complicating factor in the deterioration of an already compromised immune system ${ }^{45}$. We identified lower levels of education and protective cytokine IL-10, and higher poverty rates (evaluated using the SSI) and use of illicit drugs, smoking, and alcoholism among the HIVpositive women. These factors may interfere in health care and lead to poor outcomes in these women. Therefore, we suggest that health policies should be created to specifically address these factors in this population.

\section{Acknowledgments}

We offer our deepest thanks to all women who participated in this study and the institutions that provided technical support.

\section{Financial support}

It was provided by Strategic Program to Support Research in Health (PAPES VI), National Council for Technological and Scientific Development, Oswaldo Cruz Foundation, 407.650/2012-1.

\section{Conflict of interest}

The authors declare that there is no conflict of interest.

\section{REFERENCES}

1. Ministério da Saúde (MS). Secretaria de Vigilância em SaúdeDepartamento de IST, AIDS e Hepatites Virais: Boletim Epidemiológico Aids e DST. Brasília: MS; 2016. Available from: http:// www.aids.gov.br/sites/default/files/anexos/publicacao/2016/59291/ boletim_2016_1_pdf_16375.pdf. Accessed: Jan 21, 2017.

2. Parker R, Camargo Jr KR. Pobreza e HIV/AIDS: aspectos antropológicos e sociológicos. Cad Saude Publica. 2000;16(1):89102.

3. Bastos FIPM, Szwarcwald CL. AIDS e pauperização: principais conceitos e evidências empíricas. Cad Saude Publica. 2000;16 (Suppl 1):65-76.

4. Monteiro C. Fome, desnutrição e pobreza: além da semântica. Saúde e Socied. 2003;12(1):7-11.

5. Satyaraj E. Emerging Paradigms in Immunonutrition. Top Companion Anim Med. 2011;26(1):25-32.

6. Suttajit M. Advances in nutrition support for quality of life in $\mathrm{HIV+/}$ AIDS. Asia Pac J Clin Nutr. 2007;16(1):318-22.

7. Thomas A, Mkandawire S. The impact of nutrition on physiologic changes in persons who have HIV. Nurs Clin North Am. 2006;41(3):455-68.

8. Katona P, Katona-Apte J. The interaction between nutrition and infection. Clin Infect Dis. 2008;46(10):1582-8. 
9. Sarni ROS, Souza FIS, Cocco RR, Mallozi MC, Solé D. Micronutrientes e sistema imunológico. Rev Bras Alergia Imunopatol. 2010;33(1):8-13.

10. Dantzer R, O'Connor JC, Freund GG, Johnson RW, Kelley KW. From inflammation to sickness and depression: when the immune system subjugates the brain. Nat Rev Neurosci. 2008;9(1):47-57.

11. Minkoff H, Hershow R, Watts DH, Frederick M, Cheng I, Tuomala $\mathrm{R}$, et al. The relationship of pregnancy to human immunodeficiency virus disease progression. Obstet Gynecol 2003;189(2):552-9.

12. Trowsdale J, Betz A. Mother's little helpers: mechanisms of maternal-fetal tolerance. Nat Immunol. 2006;7(3):241-6.

13. Koch C, Platt J. T cell recognition and immunity in the fetus and mother. Cell Immunol. 2007;248(1):12-7.

14. Janeway C, Travers P, Walport M, Shlomchik M. Autoimunidade e Transplante. In: Janeway C, Travers P, Walport M, Shlomchik M, editors. Imunobiologia: o sistema immune na saúde e na doença. $5^{\text {th }}$ edition Porto Alegre: Artemed; 2002. p. 557-9.

15. Marlin R, Nugeyre M, Duriez M. Decidual soluble factors participate in the control of HIV-1 infection at the maternofetal interface. Retrovirology. 2011;8:58.

16. Richardson K, Weinberg A. Dynamics of regulatory T-cells during pregnancy: effect of HIV infection and correlations with other immune parameters. PloS One. 2011;6(11):e28172.

17. Nahmias A, Schollin J, Abramowsky C. Evolutionarydevelopmental perspectives on immune system interactions among the pregnant woman, placenta, and fetus, and responses to sexually transmitted infectious agents. Ann N Y Acad Sci. 2011;1230:25-47.

18. Pfeifer C, Bunders MJ. Maternal HIV infection alters the immune balance in the mother and fetus; implications for pregnancy outcome and infant health. Curr Opin HIV AIDS. 2016;11(2):138-45.

19. Kakkar F, Lamarre V, Ducruet T, Boucher M, Valois S, Soudeyns $\mathrm{H}$, et al. Impact of maternal HIV-1 viremia on lymphocyte subsets among HIV-exposed uninfected infants: protective mechanism or immunodeficiency. BMC Infect Dis. 2014;14:236.

20. Bunders MJ, van Hamme JL, Jansen MH, Boer K, Kootstra NA, Kuijpers TW. Fetal exposure to HIV-1 alters chemokine receptor expression by CD4+ T cells and increases susceptibility to HIV-1. Sci Rep. 2014;4:6690.

21. Hanna N, Hanna I, Hleb M, Wagner E, Dougherty J, Balkundi D, et al. Gestational Age-Dependent Expression of IL-10 and Its Receptor in Human Placental Tissues and Isolated Cytotrophoblasts. J Immunol. 2000;164(11):5721-8.

22. Mocellin S, Panelli MC, Wang E, Nagorsen D, Marincola FM. The dual role of IL-10. Trends Immunol. 2003;24(1):36-43.

23. Maynard CL, Weaver CT. Diversity in the contribution of interleukin-10 to T-cell-mediated immune regulation. Immunol Rev. 2008;226:219-33.

24. McMichael AJ, Borrow P, Tomaras GD, Goonetilleke N, Haynes BF. The immune response during acute HIV-1 infection: clues for vaccine development. Nat Rev Immunol. 2010;10(1):11-23.

25. Patroclo MAA, Medronho RA. Evolução da contagem de células T CD4+ de portadores de AIDS em contextos socialmente desiguais. Cad Saude Publica. 2007;23(8):1955-63.

26. Farias N, Cardoso MRA. Mortalidade por Aids e indicadores sociais no Município de São Paulo, 1994 a 2002. Rev Saude Publica. 2005;39(2):198-205.

27. Torres HG, Ferreira MP, Dini NP. Indicadores sociais: por que construir novos indicadores como o IPRS. São Paulo Perspect. 2003;17(3-4):80-90.
28. Nunes CLX, Gonçalves LA, Silva PT, Bina JC. Características clinico epidemiológicas de um grupo de mulheres com HIV/AIDS em Salvador-Bahia. Rev Soc Bras Med Trop. 2004;37(6):436-40.

29. Romanelli RMC, Kakehasi FM, Tavares MCT, Melo VH, Goulart LHF, Aguiar RALP et al. Perfil das gestantes infectadas pelo HIV atendidas em pré-natal de alto risco de referência de Belo Horizonte. Rev Bras Saude Matern Infant. 2006;6(3):329-34.

30. Konopka CK, Beck ST, Wiggers D, Silva AK, Diehl FP, Santos FG. Perfil clínico e epidemiológico de gestantes infectadas pelo HIV em um serviço do sul do Brasil. Rev Bras Ginecol Obstet. 2010;32(4):184-90.

31. Vieira ACBC, Miranda AE, Vargas PRN, Maciel ELN. Prevalência de HIV em gestantes e transmissão vertical segundo perfil socioeconômico, Vitória, ES. Rev Saude Publica. 2011;45(4):644-51.

32. Arber S. Integrating nonemployment into research on health inequalities. Int J Health Serv. 1996;26(3):445-81.

33. Friedman RK, Bastos FI, Leite IC, Veloso VG, Moreira RI, Cardoso $\mathrm{SW}$, et al. Incidência e preditores de gestação em mulheres com HIV/Aids no Rio de Janeiro. Rev Saude Publica. 2011;45(2):373-81.

34. Fonseca MG, Travassos C, Bastos FI, Silva NV, Szwarcwald CL . Distribuição social da AIDS no Brasil, segundo participação no mercado de trabalho, ocupação e status sócio-econômico dos casos de 1987 a 1998. Cad Saude Publica. 2003;19(5):1351-63.

35. Fonseca MG, Bastos FI, Derrico M, Andrade CLT de, Travassos C, Szwarcwald CL. AIDS e grau de escolaridade no Brasil: evolução temporal de 1986 a 1996. Cad Saude Publica. 2000;16(1):77-87.

36. Lahelma E, Pietiläinen O, Ferrie J, Kivimaki M, Lahti J, Marmot $\mathrm{M}$, et al. Changes over time in absolute and relative socioeconomic differences in smoking: A comparison of cohort studies from Britain, Finland and Japan. Nicotine Tob Res. 2016;18(8):1697-704.

37. Purohit V, Rapaka RS, Schnur P, Shurtleff D. Potential impact of drugs of abuse on mother-to-child transmission (MTCT) of HIV in the era of highly active antiretroviral therapy (HAART). Life Sci. 2011;88(21-22):909-16.

38. Aagaard-Tillery KM, Silver R, Dalton J. Immunology of normal pregnancy. Semin Fetal Neonatal Med. 2006;11(5):279-95.

39. Hygino J, Vieira MM, Kasahara TM, Xavier LF, Blanco B, Guillermo LVC, et al. The impact of pregnancy on the HIV-1specific $\mathrm{T}$ cell function in infected pregnant women. Clin Immunol. 2012;145(3):177-88.

40. Mor G, Cardenas I. The immune system in pregnancy: a unique complexity. Am J Reprod Immunol 2010;63(3):425-33.

41. Bento CAM, Hygino J, Andrade RM, Saramago CSM, Silva RG, Silva AAL et al. IL-10 secreting T cells from HIV-infected pregnant women downregulate HIV-replication: effect enhanced by antiretroviral treatment. AIDS. 2009;23(1):9-18.

42. Kuller LH, Tracy R, Belloso W, De Wit S, Drummond F, Lane HC, et al. Inflammatory and Coagulation Biomarkers and Mortality in Patients with HIV infection. PloS Med. 2008;5(10):1496-508.

43. Erlandson KM, Allshouse AA, Jankowski CM, Lee EJ, Rufner KM, Palmer BE, et al. Association of Functional Impairment with Inflammation and Immune Activation in HIV Type 1-Infected Adults Receiving Effective Antiretroviral Therapy. J Infect Dis. 2013;208(2):249-59.

44. Murphy MS, Tayade C, Smith GN. Evidence of inflammation and predisposition toward metabolic syndrome after pre-eclampsia. Pregnancy Hypertens. 2015;5(4):354-8.

45. Thomas AM, Mkandawire SC. The impact of nutrition on physiologic changes in persons who have HIV. Nurs Clin North Am. 2006;41:455-68. 